\title{
Crowdfunding Donations through Charity Concert as New Media: Alternative to Entertainment Needs or Social Movements?
}

\author{
H P Pramana ${ }^{1}$, S Hastjarjo ${ }^{2}$, Sudarmo ${ }^{3}$ \\ ${ }^{1}$ Master's Degree in Communication, Faculty of Social and Political Science, Sebelas Maret University, \\ Surakarta, Indonesia, ${ }^{2}$ Department of Communication, Faculty of Social and Political Science, Sebelas \\ Maret University, Surakarta, Indonesia, ${ }^{3}$ Department of Public Administration, Faculty of Social and \\ Political Science, Sebelas Maret University, Surakarta, Indonesia \\ ${ }^{1}$ hanifprahita@student.uns.ac.id, 25ri.hastjarjo@staff.uns.ac.id, ${ }^{3}$ sudarmo63@yahoo.com
}

\begin{abstract}
The purpose of this research is to be an empirical part of examining how crowdfunding platform collaboration with other media can create "new media." Also, the question of how this new form can provide, only entertainment or adding further value, as playing a role in mobilizing society awareness. Using a qualitative case study method with an interpretive paradigm, it was found that actors or influencers as part of initiator crowdfunding donations play a significant role in moving the community and society to make donations to attract a wider audience. They encouraged and influence community behavior to be more involved in social fundraising campaigns. This study showed that intrinsic motivation affects more than extrinsic motivation and found that this type of crowdfunding can fulfill whether entertainment or social movement in the community. It also allows us to understand better and even guide to maximize the potential future of crowdfunding donations.
\end{abstract}

Keywords: crowdfunding donations, charity concert, new media, entertainment, social movements

\section{Introduction}

Technology and information are developing quickly and rapidly to facilitate humans in social interaction. Generally, technological developments only make it easier for people to be expending. However, now users can also participate, create social projects, share campaigns, influence the community, and fellow users to do productive and giving things through the fundraising movement. Crowdfunding can be interpreted as a business in the form of fundraising aimed at social activities through a charity platform or used as venture capital. Three types of crowdfunding are based on rewards to funders, namely rewards or donations (receives financial or non-financial rewards), equity (receives compensation in the form of shares), and lending (receives refund and interest) [1].

In Indonesia, various projects are found that utilize crowdfunding to achieve social goals. In contrast, the project objectives must be realistic, marked with clear project objectives so that donors will decide to donate or not. This study focus is on crowdfunding donations, which is a type of fundraising that is implemented with the aim of charitable activities and not to seek personal or group profit. The increase in charity campaigns through donationscrowdfunding is not accompanied by sufficient literature, especially since most of them take a Western context (Europe and US) [2] [3]. Meanwhile, a little literature in the Eastern context 
was done by Hsu, Liang, \& Tien [4]. Research conducted by Yu Kang Lee \& Chun Tuan Chang in Taiwan regarding the behavior of donations found that the community who donated was influenced by extrinsic factors [5]. Empirical studies in Indonesia serve to increase relevant information about charity behavior in the Asian context.

The development of internet users in the world has reached more than 3.4 billion so that placing online sites is essential and cannot be denied. This site has various characteristics, such as varied content, interactivity, flexible design, and the low cost makes the website an attractive public relations medium. Donation-based crowdfunding collaboration platforms with other media such as television, YouTube, and other social media with different packages such as charity concerts and other social projects have encouraged researchers to find out more. The question including, how is the work of crowdfunding as new media, and the current technologies support crowdfunding work? What role do an influencer and their community play in crowdfunding work? And how can they be as social movement agenda? Moreover, the study tries to detect what motivation that could enable individuals to boost their fundraising efforts through donations.

\section{Literature Review}

Although there is evidence that still has the potential for a more significant "crowd" on the internet, it is suspected that there is always the potential for "sleeping" people to be offered or being mobilized through the activities of crowdfunding platforms. The "crowd" system in every crowdfunding project illustrates a limited number of supporters [1]. Kitabisa.com, established in 2013, is one of the crowdfunding platforms to raise funds for donations (fundraising) that are popular in Indonesia. Based on online technology for creating donation pages, this platform helps individuals, communities, organizations, or companies to create campaigns or distribute charity. Using the \#OrangBaik tagline, the sites provide pages to be able to donate at any time [6]. Crowdfunding in Indonesia is starting to become a public concern and more familiar with this platform after getting success brings a variety of benefits to support social activities, business, entertainment, and encourage social that is increasingly developing in the following years and become a solution for social needs. Yet fundraising is a vibrant, innovative, and highly professional industry [7].

Online communities are those that are used as virtual spaces where people interact to communicate, exchange information or resources, and learn [8]. Sobat ambyar community is a group of young people who are categorized as millennials who voluntarily interrelate between individuals in a virtual community. This community has the same interest in enjoying the song of Didi Kempot to express of voice broken hearts, longings, unrequited love, by joining in singing and pervading the nicknames of "sad-boy" and "sad-girl." However, sobat ambyar in this context is a symbol and identity for a community. Moreover, the development of communication technology strongly supports this phenomenon. Social media can bring campursari music, Javanese traditional music, to be enjoyed by various groups, even generation Z . Lifestyle differences between generations indicate that each generation has different understandings, expectations, attitudes, and values.

In implementing the campaign, the platform does not only play a role in raising campaign funds but also, at the same time, increasing public awareness about \#OraMudik and issues related to preventing the spread of Covid-19. A social movement is a movement consisting of campaigns or actions carried out by organized groups of individuals. It is useful for people to 
be able to repair or maintain not particular. Understanding social movements is discussing how concepts, ideas, individuals, events, and organizations are interrelated with one another in carrying out collective actions, carried out in contexts and carried out within a specified period. Along with the development of technology and communication patterns, social movements have also changed [9].

\section{Method}

This research is a qualitative study using case study research with an interpretive paradigm. This study discusses the phenomenon that is happening, the ongoing research subject, both about attitudes, behaviors, motivations, actions to get a complete and in-depth view from the viewpoint of participants who try. The object of the research is the interaction that exists in the social media platform Youtube (which is broadcast live on the Kompas TV channel) in a concert titled \#SobatAmbyarPeduli with influencers Didi Kempot and Host by Rosiana Silalahi. It was chosen because it is a social campaign with fundraising through a crowdfunding platform with massive results. Research subjects were viewers of a charity concert event in fundraising, which was carried out on the book site. Data sources used are primary data and secondary data. The research sample of primary data is done by purposive random sampling, where the researcher has determined the characteristics of the sample to be interviewed as informants who meet the specified criteria. Secondary data obtained from conversations in the comments column on Youtube and Twitter during the event, other information from the website-blog of kitabisa.com, and news in the online mass media. Data validity is done by triangulating primary data using information from six respondents. The selected respondents are respondents who enjoy charity concerts and take part in donations conducting an initial survey through the Instagram media to ensure respondents watch the \#SobatAmbyarPeduli charity concert.

\section{Results And Discussion}

New media provide more interactive and personal communication. The Internet offers virtual meeting places that add knowledge, expand the social world, and facilitate the sharing of perspectives across the globe. However, Lev Manovich prefers to see new media as a result of the merging of logistics with the scientific logistics of communication in a media concept, the combination of these two scientific fields can give uniqueness or privilege to the idea of media and ultimately shape the character of new media [10].

In recent years, the diffusion process of innovation in business processes has become increasingly diverse and challenging. Several influences on potential users include network externalities, word of mouth, and social signals. The adaptation process of the crowdfunding industry faces a slow rate of spread in the Asian market even though the profit is quite significant, especially not donations due to the failure of adoption behavior [11]. Furthermore, previous studies examining factors in web-based technology conclusively concluded that attributes, in particular, relative advantage, usage, observability, and multiplication, were the most frequently cited factors for adopting innovation [12][13].

Rogers introducing the Innovation Diffusion Theory (IDT), and based on that, Littlejohn et al. explain that there are four critical elements in IDT. There are four elements to describe the 
effectiveness of the deployment and the rate of adoption of the innovation: (1) time; (2) innovation itself; (3) communication channels; and (4) social system. IDT is a theory used to explore the reasons for individuals to adopt an innovation or new technology. Community ideas and support for new concepts offered through live streaming and collaborating with crowdfunding as a fundraising platform are quite interesting to look at. A significant increase in successful projects funded and members incorporated since 2016 proves that Indonesia is a good market for developing crowdfunding. This also shows the process of adoption of technology in society and minimal resistance within it. Based on Dutta-Bergman's theory of complementary channel theory, it explains how new channels are used in conjunction with old channels. This theory is based on selective exposure and the method of usability and gratification. Correctly, people can choose what channels and media they display, and they accept the disclosure based on the gratuities received [14]. Following this theory, the collaboration between crowdfunding as a fundraising media and YouTube social media as live streaming, the new media does not replace face-to-face communication; both channels encourage more communication using both in the same way.

Nowadays, in a globalized world, art cannot be separated from the business. Social media and, in particular, crowdfunding, have served this purpose. They offer a way to communicate and get feedback from the public and potential supporters and carry out the natural selection on projects thanks to the wisdom of the crowd. The process of community participation can provide an essential avenue for disseminating information and health interventions during a pandemic, especially with the concept of entertainment. In essence, all of these efforts are about a shared concept that when lines of communication are open in a community, and all voices are encouraged to express themselves, in the hope that their ideas will be recognized and considered, more solutions and more creative solutions can emerge.

Five dimensions for analyzing crowdfunding phenomena did by observing the person who created the project, campaign supporters, funding platforms used, the campaign itself, and the results of crowdfunding. Positive feelings will arise when you participate in a donation. Donors see the need for a positive narrative of a project in their efforts to help others before deciding to donate. This proves that the community prefers a crowdfunding model that promotes social schemes. Donors in crowdfunding usually know the purpose of the project through advertising or other internet media. The social projects chosen are the ones that offer the most utility for them. Furthermore, consideration of the benefits put forward by the initiators of the project tends to increase support from the audience. Influencers are critical people in the network that influence the opinions of others. In a charity concert organized by an influencer Didi Kempot, in addition to an invitation to donate through kitabisa.com/sobatambyarpeduli, Didi also urged people to stay at home so that they could break the chain of pandemic transmission to other regions in Indonesia. Through this charity, Didi advised the community to stay at home and not go home \#Mudik. As we know, the reputation of the initiator is positively related to the credibility of the project. Furthermore, the popularity of a project is more influenced by the empathy of donors.

The growing of digital public space, the internet, and the power of social media form platforms that function as "public sphere." Social change cannot happen overnight, social networking sites have challenged this idea by suggesting the possibility of mobilizing mass participation [10][15]. The convergence between social movements and new media gives rise to uniqueness. Besides, it brings about individual participation because new media that affects individuals can create an identity, so it does not require a significant responsibility. Social movements are not only targeting political issues, in terms of disaster or epidemics, but social problems are also often campaigned for mutual awareness and unity. It can also be brought 
about by social movements due to the inconvenience of the community towards changes that occur in their lives.

Cyberactivism is a terminology in the era of 2.0 that is used to describe internet activity activities in general and individually as a new form of communication activities as a catalyst for the exchange of social change. Cyberactivism can be categorized as a new social movement because the information transfer process is carried out more through cyberspace. The internet can expand and support messages that can lift the social change movement. During the concert event, there was a running text that continued to display messages between donors. The primary thing of a social movement is that which is connected with individuals and groups or communities collaborating into a sizeable collective action that needed to support resources, such as encouraging, material, energy, and so on to help each other.

The community considers charity concert by opening a donation as a new alternative that can reach people throughout Indonesia. We can see that the running text displayed by donors contains a message of enthusiasm and togetherness to fight against a pandemic. The use of crowdfunding is also following Indonesian culture, namely the spirit of cooperation. Then, from various data on social media, we can also conclude that in addition to the entertainment obtained by the audience, such as the purpose of watching concerts as generally, but also gathered information that viewers of this event were deliberately aimed at making donations. Based on research conducted by Chen et al., 2016 it is said that the concluding message combined with emotional framing from an advertisement has a positive influence in controlling donors to want to make donations, as we can see kitabisa.com with \#OrangBaik tagline [16].

The importance of trust in crowdfunding is an embodiment of individual or community confidence in determining decisions in choosing a forum and a project to assist. The existence of new media is often utilized in carrying out social projects as communication media, one of which is a social campaign aimed at the dimensions of social change. One of these changes is to bring changes to the community, in this case, is a way of donating and crowdfunding or raising funds, as well as raising public awareness to be more alert to the health hazards posed by Covid-19. But one thing is sure, the project objectives and utilization of the collected funds need to be monitored and transparent so that trust between the donor and the initiator of the project can go hand in hand.

The 2018 World Giving Index report places Indonesia as the most generous country with three criteria, namely helping a stranger, donation money, and volunteering time. This underlies the development of crowdfunding in Indonesia to develop rapidly. The focus in crowdfunding is collecting lots of small donations ('crowd' in crowdfunding). The motivation in crowdfunding is divided, namely intrinsic and extrinsic. Intrinsic motivation is based on participation and awareness to help each other achieve project success (psychographics), and extrinsic motivation is based on the need for rewards, benefits such as investment (demographic and socio-economic) [17]. Based on this research, it was found that Indonesian people are more likely to use intrinsic than extrinsic. This is based on the first, related to collectivist culture and religion in the Asian context to be a driver in increasing charity giving [18]. Second, Indonesia consists of a larger population of women than men. Based on gender research, emotionally, men are more likely to contribute to political groups, civil rights groups, and cultural organizations. In contrast, women are more likely to support services for the homeless and medical and health care charities [19].Third, we found the fact that the amount of individual donation is $10.000 \mathrm{Rp}$, indicate socio-economic is behind psychographic and awareness. A study says that giving and donating can make people happier. In this interview also found that most of the respondents enjoyed the charity concert with 
entertainment and donations while enjoying only as viewers of the show as entertainment are minor. All respondents responded to the charity concert given to move the community together to fight the pandemic.

\section{Conclusions}

Indonesian society was faced with limited social interactions, economic downturns, and health threats during the Covid-19 pandemic. The presence of crowdfunding as an online media by utilizing technology seeks to achieve the goals of success of a social project carried out by raising funds. Charity concert from the house titled \#SobatAmbyarPeduli raised the concept of crowdfunding through the website kitabisa.com in collaboration and with television channels, youtube, various influencers, and characterized as "new media." Kitabisa.com is an example of new social technology and media construction, which then drives a positive trend in the world of fundraising in Indonesia. Lastly, the cultural, geographic, religious shape the empathy to affect intrinsic than extrinsic to help a campaign of social projects success.

\section{References}

[1] J. Hemer, “A Snapshot on Crowdfunding," Work. Pap. Firms Reg., vol. No. R2/201, no. Fraunhofer Institute for Systems and Innovation Research ISI, 2011.

[2] R. Bennett, "Impulsive donation decisions during online browsing of charity websites," $J$. Consum. Behav., vol. 134, no. June, pp. 116-134, 2009, doi: 10.1002/cb.

[3] K. Panic, L. Hudders, and V. Cauberghe, "Fundraising in an Interactive Online Environment," Nonprofit Volunt. Sect. Q., pp. 1-18, 2015, doi: 10.1177/0899764015587715.

[4] J. L. Hsu, G. Liang, and C. Tien, "Social Concerns and Willingness to Support Charities," Soc. Behav. Pers., vol. 33, no. 2, pp. 189-200, 2005, doi: 10.2224/sbp.2005.33.2.189.

[5] Y. Lee and C. Chang, "Who Gives What to Charity? Characteristics Affecting Donation Behavior," Soc. Behav. Pers., vol. 35, no. 9, pp. 1173-1180, 2007.

[6] Herna, Hiswanti, Hidayaturahmi, and A. A. Putri, "Strategi Komunikasi Media Sosial untuk Mendorong Partisipasi Khalayak pada Situs Kitabisa.com," J. Komun. Pembang., vol. 17, no. 2, pp. 146-156, 2019.

[7] J. Andreoni, “Toward a Theory of Charitable Fund-Raising," J. Polit. Econ., vol. 106, no. 6, pp. 1186-1213, 2015.

[8] R. E. Kraut and P. Resnick, Building Successful Online Communities Evidence-Based Social Design. The MIT Press Cambridge, Massachusetts London, England, 2011.

[9] M. Poster, “'Critical Theory and TechnoCulture: Habermas and Baudrillard.' In The Second Media Age.," no. Cambridge: Polity Press, 1992., 1992.

[10] L. Manovich, The language of new media. The MIT Press (2001).pdf, 2001.

[11] Q. Yang and Y. C. Lee, "An investigation of enablers and inhibitors of crowdfunding adoption: Empirical evidence from startups in China," Hum. Factors Ergon. Manuf. Serv. Ind., no. September 2018, 2019, doi: 10.1002/hfm.20782.

[12] Y. Liu and H. Li, "Mobile internet diffusion in China: an empirical study," Ind. Manag. Data Syst., vol. 110, no. 3, pp. 309-324, 2010, doi: 10.1108/02635571011030006.

[13] D. Papies and M. Clement, "Adoption of New Movie Distribution Services on the Internet Adoption of New Movie Distribution Services on the Internet," J. Media Econ., vol. 21:3, no. December 2014, pp. 37-41, 2008, doi: 10.1080/08997760802300530.

[14] M. J. Dutta-Bergman, "Interpersonal communication after 9/11 via telephone and internet: A theory of channel complementarity," New Media Soc., vol. 6, no. 5, pp. 659-673, 2004, doi: 
$10.1177 / 146144804047086$.

[15] S. Dey, "Let There Be Clamor : Exploring the Emergence of a New Public Sphere in India and Use of Social Media as an Instrument of Activism," J. Commun. Inq., pp. 1-21, 2019, doi: 10.1177/0196859919827319.

[16] S. Chen, S. Thomas, and C. Kohli, "What really makes a promotional campaign succeed on a crowdfunding platform? Guilt, utilitarian products, emotional messaging, and fewer but meaningful rewards drive donations," J. Advert. Res., vol. 56, no. 1, pp. 81-94, 2016, doi: 10.2501/JAR-2016-002.

[17] F. Ferreira and L. Pereira, "Success factors in a reward and equity based crowdfunding campaign," 2018 IEEE Int. Conf. Eng. Technol. Innov., pp. 1-8, 2018.

[18] A. Zhang et al., "The Antecedents of Help Giving in Chinese Culture: Attribution, Judgement of Responsibility, Expectation Change and The Reaction of Affect," Soc. Behav. Pers., vol. 35, no. 1 , pp. $135-142,2007$.

[19] R. Newman, "Gender differences in philanthropy.," Fund Raising Manage., vol. 31, pp. 28-29., 2000 . 